\title{
Goals, Emotions, and Emotion Regulation: Perspectives of the Control-Value Theory
}

\author{
Commentary on Tyson, Linnenbrink-Garcia, and Hill
}

\author{
Reinhard Pekrun Elizabeth J. Stephens
}

University of Munich, Munich, Germany

\author{
Key Words \\ Achievement goals $\cdot$ Control-value theory $\cdot$ Emotion regulation
}

Recent research has started to explore the role of emotions as outcomes and antecedents of achievement goals [Linnenbrink, 2007; Linnenbrink \& Pintrich, 2002; Pekrun, Elliot, \& Maier, 2006, 2009]. Emotion regulation, however, has not yet been directly addressed as part of the dynamics of goal-driven achievement strivings. The theoretical framework presented by Tyson, Linnenbrink-Garcia, and Hill [this issue] is a pioneering attempt to address this gap in the achievement goal literature. In our view, this innovative framework is a major step forward in achievement goal research, for two reasons. First, since achievement-related emotions and affect have been shown to be important outcomes of achievement goals as well as mediators of their performance effects [Linnenbrink, 2007; Pekrun, Elliot, \& Maier, 2009], the regulation of these emotions may be critically important for explaining the functions of achievement goals. The framework provided by Tyson et al. sets the stage for exploring this potential role of emotion regulation. Second, research on goals, emotions, and emotion regulation has been in a fragmented state to date [Pekrun \& Schutz, 2007]. Such fragmentation hampers cumulative scientific progress in the field. In their framework, the authors succeeded in conceptually integrating a vast array of literatures that are relevant for explaining the relationships between achievement goals, emotions, emotion regulation, academic performance, and their antecedents in family and school environments. The framework thus represents an important advancement towards creating a unified science of human achievement strivings.

Tyson et al. set out by noting the inconsistencies in the research literature on performance effects of achievement goals. For none of the three most often researched achievement goals (i.e., mastery-approach, performance-approach, and performance-avoidance goals), the evidence on performance effects is fully consistent [Linnenbink-Garcia, Tyson, \& Patall, 2008]. However, as argued by the authors,

\begin{tabular}{ll}
\hline KARGER & $\odot$ 2009 S. Karger AG, Basel \\
Fax +41 61 306 12 34 & 0018-716X/09/0526-0357\$26.00/0 \\
$\begin{array}{l}\text { E-Mail karger@karger.ch } \\
\text { www.karger.com }\end{array}$ & $\begin{array}{l}\text { Accessible online at: } \\
\text { www.karger.com/hde }\end{array}$
\end{tabular}

Reinhard Pekrun

Department of Psychology, University of Munich Leopoldstrasse 13, DE-80802 Munich (Germany) Tel. +498921805149, Fax +498921805250 E-Mail pekrun@lmu.de 
it may be that inconsistencies regarding the effects of mastery goals can be explained by taking type of task into account. Furthermore, among the three types of goals, the evidence on performance-avoidance goals is least inconsistent, in most cases showing detrimental performance effects for these goals. In contrast, the ambiguity of performance-approach goal effects remains something of a mystery in achievement goal research and is in clear need of a better explanation.

The solution proposed by the authors is to take emotional responses and the regulation of emotions into account. They review research showing that various emotions can be debilitative or facilitative for academic performance, and that these emotions are influenced by students' achievement goals, thus functioning as mediators of goal effects. Enjoyment and positive affect thought to be facilitative for performance are promoted by mastery-approach goals, and debilitative anxiety by performance-avoidance goals. In contrast, performance-approach goals are posited to be related both to emotions that can faciliate performance, such as hope for success, and to emotions that can undermine performance, such as anxiety. Given these proposed ambiguous emotional effects, the authors argue that the regulation of emotions may be of specific importance for predicting whether performance-approach goals exert positive or negative overall effects on performance. From this perspective, emotion regulation is a prime candidate for elucidating the mystery of performance-approach goals.

Tyson et al. move on to review research on children's and adolescents' regulation of emotions, arguing that developmental and dispositional approaches to emotion regulation represent complementary perspectives. They then describe how different types of emotion regulation, such as reappraisal or emotion-focused regulation, can be beneficial or detrimental to outcomes such as academic performance. By implication, as argued by the authors, students pursuing performance-approach goals can well promote their performance if they are able to successfully regulate negative goal-induced emotions by using adaptive regulatory strategies. In contrast, regulatory strategies are thought to be less suited to counteract the uniformly negative effects of performance-avoidance goals, and unnecessary for mastery-approach goals promoting positive emotions that facilitate performance.

Finally, the authors also address dispositional and contextual factors that influence students' goal orientations, emotions, and emotional regulation. They review research on the role of children's temperament, parental socialization practices, and classroom goal structures. This review also outlines how the effects of family and school environments can combine, and how the fit between individual propensities and the individual's environments can affect the adoption of both achievement goals and strategies of emotion regulation.

In creating an overarching theoretical framework, such as the one proposed by Tyson et al., it seems inevitable that some relationships between variables are portrayed in high resolution, while the resolution is less fine-grained for other components. In the following sections, we outline thoughts about how to further develop the framework by Tyson et al. in order to enrich some of its predictions. These thoughts are informed by Pekrun's [Pekrun, 2006; Pekrun, Frenzel, Goetz, \& Perry, 2007] control-value theory of achievement emotions. We first address emotions as outcomes of achievement goals, highlighting the similarities and differences between the approaches by Linnenbrink and Pintrich [2002] and Pekrun, Elliot, \& Maier [2006, 2009]. Next, performance effects of emotions are discussed. In conclu- 
sion, we suggest taking into account concepts and findings of related research on coping, and discuss implications of the causal reciprocity of relationships for conceptualizing students' emotional regulation and relations with their environments.

\section{From Goals to Emotions: Complementary Views}

Current conceptions of goal effects on emotions show substantial convergence, as pointed out by the authors. However, this convergence is not complete. Specifically, the Linnenbrink and Pintrich [2002] model posits that achievement goals promote attentional focusing on the rate of progress towards success or away from failure, which in turn is thought to contribute to the arousal of different emotions. Mastery goals are thought to promote perceptions of progress towards success, thus facilitating emotions such as happiness; performance-approach goals are thought to promote perceptions of insufficient progress towards success due to competition with others, thus facilitating emotions such as sadness; and performance-avoidance goals are thought to facilitate anxiety. In contrast, the model by Pekrun, Elliot, \& Maier [2006, 2009] posits that achievement goals promote attentional focusing on the success and failure outcomes themselves, which in turn promotes different emotions. Mastery goals are thought to promote positive perceptions (i.e., perceived controllability and positive values) of achievement activities, thus facilitating activityrelated enjoyment and reducing boredom; performance-approach goals positive perceptions of success outcomes, thus facilitating outcome-related emotions such as hope and pride; and performance-avoidance goals negative perceptions (i.e., perceived uncontrollability and negative values) of failure outcomes, thus facilitating outcome-related anxiety, shame, and hopelessness.

Both approaches share the assumption that goal effects on emotions are mediated by self-related cognitive appraisals. However, they differ in the following two ways. First, the Linnenbrink and Pintrich [2002] model addresses outcome-related achievement emotions pertaining to success and failure. The model by Pekrun, Elliot, \& Maier [2006, 2009] additionally incorporates activity-related emotions pertaining to the achievement activities themselves, such as enjoyment and boredom (see Pekrun's [2006] outcome focus $\times$ valence taxonomy of achievement emotions differentiating outcome vs. activity emotions). These emotions are posited to be influenced by mastery goals. Second, in the Linnenbrink and Pintrich [2002] model, goal effects on outcome-related emotions are thought to be mediated by perceptions of progress towards or away from the outcome; in the model by Pekrun, Elliot, \& Maier [2006, 2009], they are thought to be mediated by perceptions of the controllability and value of the outcome. The predictions about outcome-related emotions that can be derived from these different views about mediation show considerable similarity, but there are also differences (e.g., regarding the links between performance goals and sadness).

Most likely, both kinds of mediating cognitions play a role in the arousal of outcome-related achievement emotions, implying that the two approaches are complementary rather than mutually exclusive. Clearly, empirical research is needed to clarify these mediating cognitive processes so that the relative importance of appraisals of control, value, and progress towards outcome in goal-induced achievement emotion arousal can be judged. Studies should analyze how these different ap- 
praisals are shaped by achievement goals as well as by features of tasks and achievement settings, and how they combine in the arousal of achievement emotions [Pekrun, Lichtenfeld, \& Maier, 2009b]. Certainly more first-stage research analyzing the overall linkages between achievement goals and emotions is still needed, but second-stage research analyzing the underlying mechanisms will eventually be necessary to better understand these linkages.

\section{From Emotions to Performance: Cognitive and Motivational Mechanisms}

In their framework, Tyson et al. focus on the role of debilitative emotions that can be triggered by performance goals and undermine academic performance. They convincingly argue that emotions reducing performance can vary both on the valence (pleasant vs. unpleasant) and arousal (activating vs. deactivating) dimensions describing emotions; as posited by the authors, even activating pleasant emotions such as pride could be detrimental if they were extreme. To explain these negative effects, task-irrelevant thinking that produces cognitive interference is discussed as one primary mechanism.

For further elaborating hypotheses on emotion effects, we suggest examining the influence of emotions on the various cognitive and motivational processes underlying learning and performance. As shown by experimental research on mood, affective states can influence a wide range of cognitive processes, including perception, attention, memory storage and retrieval, decision making, and cognitive problem solving [Clore \& Huntsinger, 2007, 2009; Kuhbandner et al., 2009; Lewis \& Haviland-Jones, 2000]. Specifically, in line with the arguments of Tyson et al., it has been shown that emotional states consume cognitive resources by focusing attention on the object of emotion [Ellis \& Ashbrook, 1988]. The consumption of cognitive resources for task-irrelevant purposes implies that fewer resources are available for task completion, thereby reducing performance [Meinhardt \& Pekrun, 2003]. Furthermore, mood can enhance mood-congruent memory recall [Levine \& Burgess, 1997], with positive mood facilitating the retrieval of positive self-related and taskrelated information, and negative mood sustaining the retrieval of negative information [Olafson \& Ferraro, 2001], thus influencing motivation based on self-appraisals. Finally, mood has been shown to influence cognitive problem solving, with positive mood promoting flexible and creative ways of solving problems, and negative mood promoting more rigid, detail-oriented, and analytical ways of thinking [Clore \& Huntsinger, 2007, 2009].

By implication, it can be assumed that emotions influence students' cognitive performance by affecting their cognitive resources, motivational processes, and ways of solving problems. The overall effects of any given emotion on performance will likely depend on the nature of the mechanisms facilitated by the emotion, the interplay of these mechanisms, and their interactions with task demands. For emotions varying in terms of valence and activation, the following can be assumed, as proposed in Pekrun's control-value theory of achievement emotions (see the cognitive-motivational effects model which is part of the theory) [Pekrun, 1992, 2006].

Regarding pleasant affect, activating positive emotions such as task-related enjoyment should preserve cognitive resources and focus attention on the task at hand, foster interest and intrinsic motivation, facilitate the use of flexible learning strate- 
gies such as elaboration and organization of learning material, and promote flexible self-regulation of learning, thus typically benefitting performance. As has also been argued by Tyson et al., one important limiting condition is that these emotions are directed towards the task (task-intrinsic positive emotions) [Pekrun, Goetz, Titz, \& Perry, 2002]. In contrast, positive emotions that are directed towards the self or alternative reference objects (task-extrinsic emotions) distract attention away from the task, thus undermining performance. In contrast to the beneficial effects of task-intrinsic activating positive emotions, deactivating positive emotions such as relief and relaxation may exert ambiguous effects by reducing task attention, undermining current motivation, and promoting superficial information processing, while at the same time reinforcing motivation to subsequently reengage with the task.

Regarding unpleasant affect, activating negative emotions such as anger, anxiety, and shame are also posited to exert effects that are quite ambiguous. For example, test anxiety can consume cognitive resources by inducing worries about possible failure and can undermine subject matter interest; at the same time, however, anxiety can strengthen motivation to avoid failure and facilitate more rigid ways of learning such as simple rehearsal of test material. Deactivating negative emotions such as boredom and hopelessness, on the other hand, are expected to uniformly impair performance by producing task-irrelevant thinking and undermining any kind of task-related motivation and strategy use.

For unpleasant emotions, the available evidence is largely in line with these propositions. For example, while the performance effects of test anxiety are often negative, they have been shown to be positive for some individuals and some types of tasks [Pekrun \& Hofmann, 1996; Zeidner, 1998]. Accordingly, sample correlations for test anxiety and students' academic performance can vary from negative to positive [Hembree, 1988]. Similarly, the effects of anger and shame proved to be ambiguous [Lane, Whyte, Terry, \& Nevill, 2005; Turner \& Schallert, 2001]. In contrast, the linkages of boredom and hopelessness with academic performance proved to be uniformly negative, in line with expectations [Pekrun et al., 2002]. For pleasant emotions, however, the little research evidence available is less clear-cut. Regarding deactivating positive emotions such as relief and relaxation, empirical evidence is largely lacking; for positive emotions classified as activating, such as enjoyment, hope, and pride, the evidence is mixed. Whereas a number of studies have demonstrated positive associations with academic performance, others produced null findings [Linnenbrink, 2007; Pekrun et al., 2002; Pekrun, Elliot, \& Maier, 2009]. It may be that emotions such as enjoyment were misclassified as arousing in some studies, or that enjoyment of learning signals that 'all is well,' thus suggesting that further effort is not needed (for a discussion of effects of positive emotions, see Aspinwall [1998], Clore and Huntsinger [2007, 2009], Fredrickson [2001], and Pekrun [2006]).

Similar to the mystery regarding ambiguous performance effects of approach achievement goals addressed by Tyson et al., there seems to be a mystery regarding the performance effects of positive achievement emotions. Obviously, as goals and emotions are interrelated, these two mysteries may be interrelated as well. More specifically, both performance-approach goals and mastery-approach goals can produce ambiguous effects on performance [Linnenbrink-Garcia et al., 2008]. As argued by Pekrun, Elliot, \& Maier [2009], this ambiguity of approach goal effects may be partly due to the ambiguity of the positive emotions that mediate these effects, in addition to the ambiguity of attempts to regulate any negative emotions evoked by these goals. 


\section{Emotion Regulation, Coping, and Reciprocity of Relationships}

In addressing emotion regulation as a potential moderator of goal effects on performance, Tyson et al. review developmental work on emotion regulation, as well as research on individual differences in emotion regulation. Coping studies represent an additional tradition of research, providing concepts and findings that can be used to further enrich the framework. Clearly, emotion regulation and coping are overlapping constructs. The term 'coping' is used to denote any behaviors aimed to deal with stressful encounters [Lazarus \& Folkman, 1984]; the term 'emotion regulation' refers to behaviors aimed to induce, modulate, or prevent emotions (typically, by upregulating positive and downregulating negative emotions). Since unpleasant emotions can be very stressful, regulating these emotions is regarded as one important domain of coping [Lazarus, 1996]. Consequently, within the tradition of research on coping, a number of studies have addressed students' regulation of test anxiety [Kondo, 1997; Norem \& Cantor, 1986; Rost \& Schermer, 1987]. Also, coping researchers have developed strategies to organize constructs of coping that could also prove useful to organize the various taxonomies of ways to regulate emotions [Skinner, Edge, Altman, \& Sherwood, 2003].

Furthermore, for a more complete understanding of goal-relevant ways to regulate emotions, it may prove helpful to take the reciprocal nature of the associations between goals, emotions, and emotion regulation into account [Linnenbrink \& Pintrich, 2002; Pekrun et al., 2002]. As posited in the control-value theory [Pekrun, 2006], emotions, their appraisal antecedents, their distal individual antecedents (including achievement goals), their environmental antecedents, and their performance outcomes are typically linked by reciprocal causation (fig. 1). By implication, attempts to regulate emotions in an academic context can involve targeting the emotion itself or related attentional processes and appraisals [Davis, DiStefano, \& Schutz, 2008], as addressed by Tyson et al. However, students' regulation of their emotions can also involve additional strategies. Conceivably, emotions can be regulated by addressing any of the elements in the cyclic feedback processes in which emotions are embedded, since all of these elements can influence the emotion.

From the perspective of the control-value theory, the following ways of regulating emotions in an academic context may be of specific importance [Pekrun, 2006] (fig. 1): (1) emotion-oriented regulation (directly targeting the emotion, e.g., by using relaxation techniques or taking drugs); (2) appraisal-oriented regulation (changing appraisals, e.g., reappraisal and attributional retraining) [Gross, 1998; Ruthig, Perry, Hall, \& Hladkyj, 2004]; (3) regulation of goals and beliefs (changing achievement goals and achievement-related beliefs which influence appraisals and emotions, e.g., by cognitive restructuring therapy); (4) competency training targeting subject matter knowledge or study strategies; (5) selection of tasks and environments (self-selecting adequate tasks and academic environments that match individual goals and competencies); (6) social support seeking (making better use of task materials and environments by seeking help) [Karabenick \& Newman, 2006], and (7) optimization of tasks and environments (regulating environments by changing tasks and the achievement climate in classrooms). In principle, all of these strategies can be applied by the individual learner, although possibilities to self-select or modify tasks and environments may be limited in traditional academic settings. 


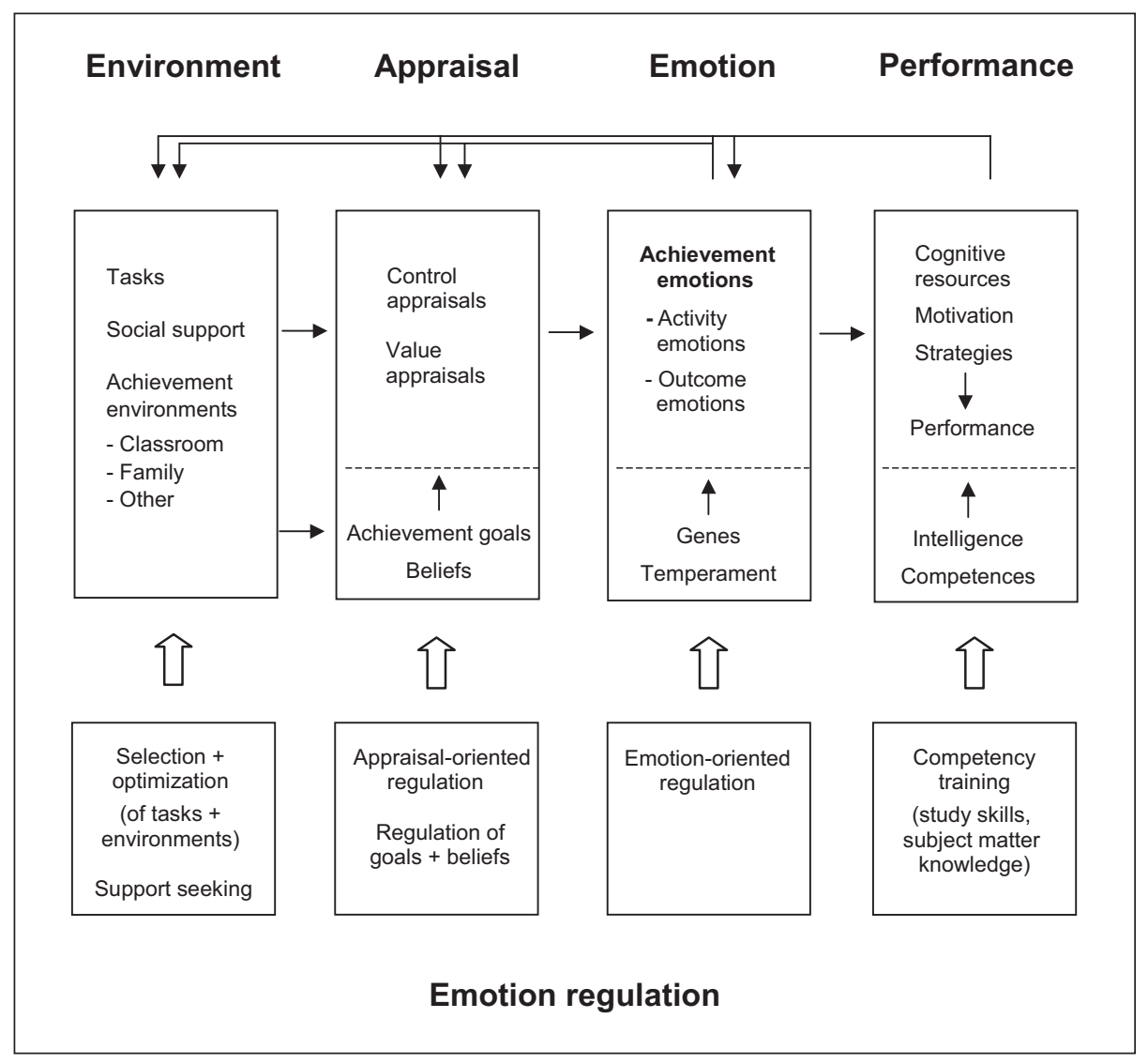

Fig. 1. Emotion regulation in the control-value theory of achievement emotions.

Given the reciprocity of linkages between emotions, their antecedents, and their outcomes, all of these different strategies may be functionally interrelated and may serve multiple purposes. For example, increasing study skills may help to increase self-confidence, thus alleviating anxiety and increasing enjoyment, while at the same time, directly benefitting performance. Furthermore, while some of these strategies may often be more adaptive than others, it would be misleading to assume that any one strategy is always adaptive or maladaptive in terms of positively or negatively affecting performance and well-being. For example, directly targeting negative emotions is often regarded as maladaptive, but can be helpful to restore energy for later successful attempts to prepare for an important exam. Conversely, problem-focused persistence when dealing with difficult material can hinder a student from giving up unattainable achievement goals and searching for more realistic alternatives.

Finally, bidirectionality may also be important for explaining the relationships between individuals and their environments. As convincingly argued by Tyson et al., 
family and school environments jointly influence students' achievement goals, their emotions, and their emotion regulation. In addition, it can be taken into account that students reciprocally influence their environments. Similar to the effects of different environments, reciprocal effects involving students and environments can take different forms and can lead to passive as well as active types of individual-environment interactions.

These reciprocal relations likely contribute both to individual emotion regulation and to the co-regulation of emotions linking individual students and their parents, teachers, and classmates. Reciprocity implies that emotion regulation in an academic context need not be done in social isolation. Rather, emotions can be regulated collectively. While research on human coping has traditionally studied coping as an isolated individual endeavor, recent progress in research on coping has taken collective ways of coping into account as well [Dunahoo, Hobfoll, Monnier, Hulsizer, \& Johnson, 1998]. Similarly, future research on students' emotion regulation should address collective emotion regulation in addition to individual regulation, in line with the research on collective home and classroom goal structures addressed in the Tyson et al. framework.

\section{References}

Aspinwall, L. (1998). Rethinking the role of positive affect in self-regulation. Motivation and Emotion, $22,1-32$.

Clore, G.L., \& Huntsinger, J.R. (2007). How emotions inform judgment and regulate thought. Trends in Cognitive Science, 11, 393-399.

Clore, G.L., \& Huntsinger, J.R. (2009). How the object of affect guides its impact. Emotion Review, 1, 39-54.

Davis, H.A., DiStefano, C., \& Schutz, P.A. (2008). Identifying patterns of appraising tests in first-year college students: Implications for anxiety and emotion regulation during test taking. Journal of Educational Psychology, 100, 942-960.

Dunahoo, C.L., Hobfoll, S.E., Monnier, J., Hulsizer, M.R., \& Johnson, R. (1998). There's more than rugged individualism in coping. 1. Even the lone ranger had Tonto. Anxiety, Stress, and Coping, 11, 137-165.

Ellis, H.C., \& Ashbrook, P.W. (1988). Resource allocation model of the effect of depressed mood states on memory. In K. Fiedler \& J. Forgas (Eds.), Affect, cognition, and social behavior. Toronto: Hogrefe International.

Fredrickson, B.L. (2001). The role of positive emotions in positive psychology: The broaden-and-build theory of positive emotions. American Psychologist, 56, 218-226.

Gross, J. (1998). Antecedent- and response-focused emotion regulation: Divergent consequences for experience, expression, and physiology. Journal of Personality and Social Psychology, 74, 224237.

Hembree, R. (1988). Correlates, causes, effects, and treatment of test anxiety. Review of Educational Research, 58, 47-77.

Karabenick, S.A., \& Newman, R. (2006). Help seeking in academic settings: Goals, groups, and contexts. Mahwah: Erlbaum.

Kondo, D.S. (1997). Strategies for coping with test anxiety. Anxiety, Stress, and Coping, 10, 203-215.

Kuhbandner, C., Hanslmayr, S., Maier, M.A., Pekrun, R., Spitzer, B.J., Pastötter, B., \& Bäuml, K.-H. (2009). Effects of mood on the speed of conscious perception: Behavioural and electrophysiological evidence. Social Cognitive and Affective Neuroscience, 4, 286-293.

Lane, A.M., Whyte, G.P., Terry, P.C., \& Nevill, A.M. (2005). Mood, self-set goals, and examination performance: The moderating effect of depressed mood. Personality and Individual Differences, 39, $143-153$.

Lazarus, R.S. (1996). The role of coping in the emotions and how coping changes over the life course. In C. Maletesta-Magni \& S.H. McFadden (Eds.), Handbook of emotion, adult development, and aging (pp. 289-306). New York: Academic Press.

Lazarus, R.S., \& Folkman, S. (1984). Stress, appraisal, and coping. New York: Springer. 
Levine, L.J., \& Burgess, S.L. (1997). Beyond general arousal: Effect of specific emotions on memory. Social Cognition, 15, 157-181.

Lewis, M., \& Haviland-Jones, J.M. (2000). Handbook of emotions (2nd ed.). New York: Guilford Press.

Linnenbrink, E.A. (2007). The role of affect in student learning: A multi-dimensional approach to considering the interaction of affect, motivation, and engagement. In P.A. Schutz \& R. Pekrun (Eds.), Emotion in education (pp. 107-124). San Diego: Academic Press.

Linnenbrink, E.A., \& Pintrich, P.R. (2002). Achievement goal theory and affect: An asymmetrical bidirectional model. Educational Psychologist, 37, 69-78.

Linnenbrink-Garcia, L., Tyson, D., \& Patall, E.A. (2008). When are achievement goal orientations beneficial for academic achievement? A closer look at main effects and moderating factors. International Review of Social Psychology, 21, 19-70.

Meinhardt, J., \& Pekrun, R. (2003). Attentional resource allocation to emotional events: An ERP study. Cognition and Emotion, 17, 477-500.

Norem, J.K., \& Cantor, N. (1986). Defensive pessimism: Harnessing anxiety as motivation. Journal of Personality and Social Psychology, 51, 1208-1217.

Olafson, K.M., \& Ferraro, F.R. (2001). Effects of emotional state on lexical decision performance. Brain and Cognition, 45, 15-20.

Pekrun, R. (1992). The impact of emotions on learning and achievement: Towards a theory of cognitive/motivational mediators. Applied Psychology: An International Review, 41, 359-376.

Pekrun, R. (2006). The control-value theory of achievement emotions: Assumptions, corollaries, and implications for educational research and practice. Educational Psychology Review, 18, 315-341.

Pekrun, R., Elliot, A.J., \& Maier, M.A. (2006). Achievement goals and discrete achievement emotions: A theoretical model and prospective test. Journal of Educational Psychology, 98, 583-597.

Pekrun, R., Elliot, A.J., \& Maier, M.A. (2009). Achievement goals and achievement emotions: Testing a model of their joint relations with academic performance. Journal of Educational Psychology, 101, 115-135.

Pekrun, R., Frenzel, A., Goetz, T., \& Perry, R.P. (2007). The control-value theory of achievement emotions: An integrative approach to emotions in education. In P.A. Schutz \& R. Pekrun (Eds.), Emotion in education (pp. 13-36). San Diego: Academic Press.

Pekrun, R., Goetz, T., Titz, W., \& Perry, R.P. (2002). Academic emotions in students' self-regulated learning and achievement: A program of quantitative and qualitative research. Educational Psychologist, 37, 91-106.

Pekrun, R., \& Hofmann, H. (1996). Affective and motivational processes: Contrasting interindividual and intraindividual perspectives. Paper presented at the annual meeting of the American Educational Research Association, New York.

Pekrun, R., Lichtenfeld, S., \& Maier, M.A. (2009). Anxiety of failure in achievement settings: A controlvalue model and experimental test. Paper presented at the annual meeting of the American Educational Research Association, San Diego.

Pekrun, R., \& Schutz, P.A. (2007). Where do we go from here? Implications and future directions for inquiry on emotions in education. In P.A. Schutz \& R. Pekrun (Eds.), Emotion in education (pp. 313-331). San Diego: Academic Press.

Rost, D.H., \& Schermer, F.J. (1987). Emotion and cognition in coping with test anxiety. Communication and Cognition, 20, 225-244.

Ruthig, J.C., Perry, R.P., Hall, N.C., \& Hladkyj, S. (2004). Optimism and attributional retraining: Longitudinal effects on academic achievement, test anxiety, and voluntary course withdrawal in college students. Journal of Applied Social Psychology, 34, 709-730.

Skinner, E.A., Edge, K., Altman, J., \& Sherwood, H. (2003). Searching for the structure of coping: A review and critique of category systems for classifying ways of coping. Psychological Bulletin, 129, 216-269.

Turner, J.E., \& Schallert, D.L. (2001). Expectancy-value relationships of shame reactions and shame resiliency. Journal of Educational Psychology, 93, 320-329.

Zeidner, M. (1998). Test anxiety: The state of the art. New York: Plenum. 